\title{
A novel composite scaffold of Cu-doped nano calcium-deficient hydroxyapatite/multi-(amino acid) copolymer for bone tissue regeneration
}

This article was published in the following Dove Press journal: International Journal of Nanomedicine

\author{
Ping Mou' \\ Haitao Peng ${ }^{2}$ \\ Li Zhou ${ }^{3}$ \\ Lin $\mathrm{Li}^{2}$ \\ Hong $\mathrm{Li}^{2}$ \\ Qiang Huang' \\ 'Department of Orthopedic Surgery, \\ West China Hospital, West China \\ Medical School, Sichuan University; \\ ${ }^{2}$ School of Physical Science and \\ Technology, Sichuan University; ${ }^{3}$ Core \\ Facility of West China Hospital, Sichuan \\ University, Chengdu, Sichuan Province \\ 61004I, People's Republic of China
}

Correspondence: Qiang Huang Department of Orthopedics, West China Hospital, Sichuan University, \#37 Guoxue Road, Chengdu, 61004I, People's

Republic of China

$\mathrm{Tel}+8618980606708$

Email huangqiang4325@I26.com
Background and methods: A Cu-doped composite scaffold of nano calcium-deficient hydroxyapatite (n-CDHA)/multi(amino acid) copolymer (MAC) was prepared. The structure, porosity, morphology and compressive strength of the scaffolds were characterized, the in vitro degradability in phosphate-buffered solution (PBS) and cell responses to the scaffolds were investigated, and in vivo stimulation of bone formation were analyzed.

Results: The scaffolds showed the compressive strength of approximately $12 \mathrm{MPa}$ and total porosity of about $81 \%$. Weight loss of the composite scaffolds was $63 \%$ after 16 -week immersion in PBS. $\mathrm{Cu}$ release in scaffolds showed a marked dependence on the initial amount in the scaffolds over time. Cu-doped n-CDHA/MAC scaffolds with the content of $\mathrm{Cu} 0.5 \%$ and $1 \%$ in mass ratio showed better cell responses to proliferation and differentiation of rat bone marrow stromal cells (rBMSCs) than that with no $\mathrm{Cu}$. After 12-week implantation in rabbits, $1 \% \mathrm{Cu}$-doped $\mathrm{n}$-CDHA/MAC showed better ability of angiogenesis and osteogenesis compared to $0 \% \mathrm{Cu}$-doped n-CDHA/MAC.

Conclusion: The $1 \% \mathrm{Cu}$-doped $\mathrm{n}$-CDHA/MAC composite scaffold showed good capacity of angiogenesis and osteogenesis, and the $\mathrm{Cu}$ showed positive effects on cell growth and osteogenesis. And it has potential to be used as bone regeneration scaffolds.

Keywords: calcium-deficient hydroxyapatite, multi-(amino acid) copolymer, copper, osteogenesis, degradability, cytocompatibility

\section{Introduction}

Osteonecrosis of the femoral head (ONFH) associated with alcohol abuse and/or corticosteroids $^{1}$ is a potentially devastating disease due to interruption of circulation that limits the transmission of oxygen and nutrients to femoral head. During the last several decades, early-stage joint-preserving operative techniques have been used to slow the progression of ONFH, ${ }^{2,3}$ which include core decompression, femoral osteotomy, nonvascularised bone grafting (NVBG), vascularized bone grafting (VBG) and cell-based treatment. ${ }^{4,5}$

Although core decompression can reduce the intraosseous hypertension resulting from swelling and infiltration of cells due to the progressive necrosis and provide symptomatic relief especially in hips with symptomatic, smaller-sized, pre-collapse necrosis, ${ }^{6}$ no obvious relief could be found when the femoral head collapsed. In addition, core decompression can be in combination with tantalum rods, bone substitutes, arthroscopy, and cell treatment. However, there are still debates on the results of the techniques between Western and East Asian countries. ${ }^{4}$ Femoral osteotomy allows healing and 
postpones progression by moving the necrotic region from weight-bearing area and shows favourable results. ${ }^{7-9}$ However, the complications including poor fixation and/or malposition, malunion after osteotomy are high-incidence ${ }^{5,10}$ as well as more difficult to switch to total hip arthroplasty (THA) if an osteotomy fails. ${ }^{11}$ NBVG can support the femoral head structurally and decompress the necrotic region to facilitate healing and remodelling of femoral head, but using autogenous cancellous grafting can prolong surgical time and cause additional pain of donor site, while the antigenicity and potential danger of spreading diseases for allograft implants. ${ }^{12,13}$ Although VBG can provide structural support and restore blood supply of live bone, ${ }^{14}$ yet technical difficulties and prolonged operation time are required. Also, current studies on VBG do not have a control group and are not randomized. So, there is no consensus on the true effect on the progression of osteonecrosis. ${ }^{4}$ Osteonecrosis results from lack of cells which can promote osteogenesis. So, cell therapy to potentially regenerate bone was considered. ${ }^{15} \mathrm{~A}$ recent systematic review ${ }^{15}$ concluded that cell therapy was safe for osteonecrosis and could improve clinical outcomes. Nonetheless, the authors ${ }^{15}$ suggest strict application indications for osteonecrosis should be determined and standardization of cell therapy should be established before cell-based treatment adopted. In brief, the current operative methods to treat early-stage ONFH just provide the mechanical support of necrotic region and there is no consensus on the true results of VBG on the progressive osteonecrosis. So, how to synthesize material combining osteogenesis with angiogenesis to induce bone regeneration and vascularization is significant to cure early-stage ONFH.

Angiogenesis is essential in bone regeneration because blood vessels transport oxygen and nutrients to regenerated bone, which are crucial for bone regeneration and defect restoration. Copper $(\mathrm{Cu})$, a vital trace element, could stimulate osteogenesis and angiogenesis of mesenchymal stem cells (MSCs). ${ }^{16-18}$ Simultaneously, the research ${ }^{19}$ has demonstrated that in culture medium, even the concentration of $\mathrm{Cu}$ reached up to $250 \mu \mathrm{M}$, there is no adverse and side effects for cells for continuous culture of 10 days, which shows the biosecurity of $\mathrm{Cu}$ in regions. And literature also demonstrated that doping $\mathrm{Cu}$ into biomaterials to form novel scaffolds with characteristic of slow-release of $\mathrm{Cu}$ could enhance their original angiogenesis and osteogenesis properties. ${ }^{20}$

Moreover, according to Li's research, ${ }^{21}$ nano calciumdeficient hydroxyapatite/multi-(amino acid) copolymer
(n-CDHA/MAC), an eligible degradable composite bone substitute biomaterial, consisting of inorganic n-CDHA and an amide linkage copolymer composed of 6-aminocaproic acid and other five amino acids, not only was provided with good mechanical performance, but also outstanding osteogenesis when the n-CDHA occupies $40 \mathrm{wt} \%$ of n-CDHA/MAC. And n-CDHA/MAC presented macropores with the size from 100 to 600 um and porosity of $81 \%$, which were similar to the reported literature showing satisfactory bone ingrowth and mineralized bone regeneration. ${ }^{22}$ Furthermore, the previous researches ${ }^{19,21,23,24}$ has demonstrated that n-CDHA/MAC possess excellent mechanical strength, degradability and bioactivity.

Therefore, on account of the properities n-CDHA/MAC and $\mathrm{Cu}$ respectively, we synthesized a novel composite bone substitute scaffold: $\mathrm{Cu}$-doped n-CDHA/MAC with functional properties including osteogenesis and angiogenesis. To our knowledge, this is the first study research $\mathrm{Cu}-$ doped n-CDHA/MAC for bone regeneration. So, the aim of present study is to investigate the biosecurity of the scaffolds as the foundation of the treatment of ONFH. In particular, the physical and chemical properties, the ability of angiogenesis and osteogenesis were evaluated.

\section{Material and methods Synthesis of Cu-doped n-CDHA/MAC composite}

The Cu-doped n-CDHA slurry was prepared in a reactor under $40^{\circ} \mathrm{C}$ according to a precipitation route described elsewhere. $^{25}$ Briefly, a certain amount of $\mathrm{CuSO}_{4} .5 \mathrm{H}_{2}$ O (AR, Guang dou Guanghua Sci-Tech co., Ltd) and 10 mole calcium nitrate tetrahydrate $\left(\mathrm{Ca} \quad\left(\mathrm{NO}_{3}\right)_{2} \cdot 4 \mathrm{H}_{2} \mathrm{O}\right.$, 99.2\% Aldrich) was added dropwise to 6 mole diammonium hydrogen phosphate $\left(\left(\mathrm{NH}_{4}\right)_{2} \mathrm{HPO}_{4}, 99.2 \%\right.$ Aldrich $)$, and the $\mathrm{pH}$ was continuously controlled and adjusted at 9.0 \pm 0.1 by adding $\mathrm{NH}_{4} \mathrm{OH}$ (AR, Chengdou kelong Chemical Reagent Co., Ltd). Precipitate was aged in mother solution for $48 \mathrm{~h}$, washed with $\mathrm{NH}_{4} \mathrm{OH}$ aqueous solution and alcohol (AR, Sichuan Xilong Chemical co., Ltd). Cu-doped n-CDHA with various $\mathrm{Cu} / \mathrm{CDHA}$ ratio $(\mathrm{W} / \mathrm{W}, 1.25 \%$, $2.5 \%, 5 \%$, and $12.5 \%$ ) were obtained.

The preparation method of $\mathrm{Cu}$-doped n-CDHA/MAC composite with $40 \mathrm{wt} \% \mathrm{Cu}$-doped n-CDHA was described in detail in the reference, ${ }^{21}$ and the scaffold was prepared according to the reference. ${ }^{26}$ The $\mathrm{Cu}$ in the obtained scaffolds were $0.5 \%, 1 \%, 2 \%$ and $5 \%$, respectively (Figure 1 ). 


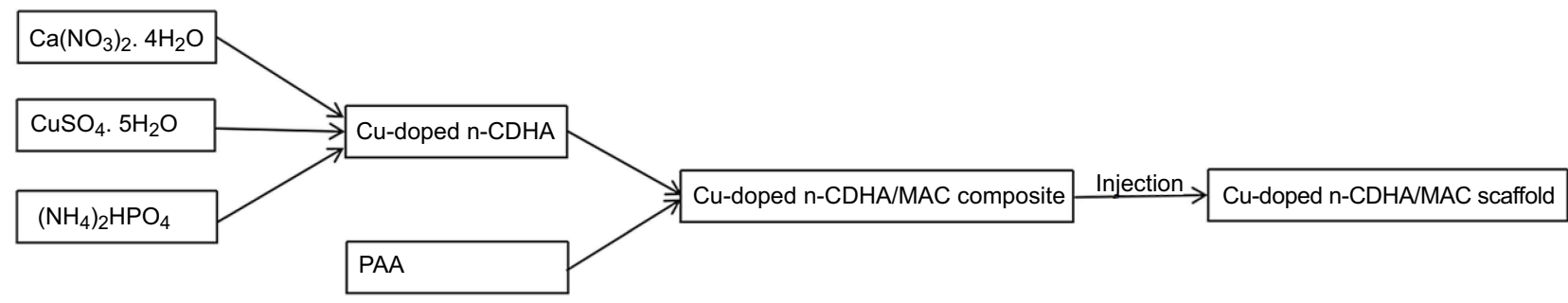

Figure I A flow chart about the preparation of scaffold.

Abbreviations: n-CDHA, nano calcium-defcient hydroxyapatite; n-CDHA/MAC, nano calcium-defcient hydroxyapatite/multi(amino acid) copolymer; PAA, polyamino acid.

\section{$\mathrm{Cu}$, porosity and morphology of the scaffolds}

The concentrations of $\mathrm{Cu}$ in scaffolds were detected by inductively coupled plasma mass spectrometry (ICP, IRIS 1,000, Thermo Electron Corporation, Waltham, MA, USA). The densities of different Cu-doped n-CDHA/ MAC composite scaffolds $(\varphi 6 \times 12 \mathrm{~mm}), \rho_{\mathrm{a}}$, were measured by the ratio of mass and volume. The skeletal densities, $\rho_{\mathrm{d}}$, was also measured with compact samples $(\varphi 6 \times 12 \mathrm{~mm})$. The pyknotic samples were handled by the same process of $\mathrm{Cu}$-doped n-CDHA/MAC composite scaffolds without foaming agent, and the total porosity was calculated by the formula: $P_{t}(\%)=\left(1-\rho_{a} / \rho_{d}\right) \times 100 \%$. Three replicates were done for each group, and the results were presented as mean $\pm \mathrm{SD}$.

Also, the morphology of $\mathrm{Cu}$-doped n-CDHA/MAC composite scaffolds was shown by Micro-CT (PerkinElmer, Quantum GX, America).

\section{Compressive strength measurement}

The compressive strengths of different $\mathrm{Cu}$-doped n-CDHA/ MAC composite scaffolds were handled by mechanical testing machine (REGER 30-50, Shenzhen Reger Co., Ltd. China) with $50 \mathrm{kN}$ load. The cross-head speed was $1 \mathrm{~mm} /$ $\mathrm{min}$, and the load was applied until the samples $(\varphi 6 \times 12 \mathrm{~mm})$ were compressed to approximately $50 \%$ in height or the samples collapsed. Three replicates were done for each group, and the results were expressed as mean $\pm \mathrm{SD}$.

\section{In vitro degradability and $\mathrm{cu}$ release in PBS}

The in vitro degradability of $\mathrm{Cu}$-doped $\mathrm{n}$-CDHA/MAC composite scaffolds was performed by soaking the scaffold samples $(\varphi 6 \times 12 \mathrm{~mm})$ into phosphate-buffered saline (PBS, $\mathrm{pH}=7.4$ ) for 16 weeks and was evaluated at different time points. We washed scaffold samples, dried them at $80{ }^{\circ} \mathrm{C}$ in vacuum oven for $4 \mathrm{~h}$ and weighed them the initial weight (Wi). The PBS was equipped with a solid/liquid ratio of $1 \mathrm{~g} / 50 \mathrm{ml}$ in polyethylene (PE) tubes, which were capped and placed in a shaking water bath $\left(37 \pm 0.5^{\circ} \mathrm{C}\right.$ and $72 \mathrm{rpm})$. At 1, 2, 4, 8, 12 and 16 weeks, the samples were washed and dried, and the residual weight (Wt) were measured. The weight loss ratio was tested according to the following formula: Weight loss $=(\mathrm{Wi}-\mathrm{Wt}) / \mathrm{Wi} \times 100 \%$. Simultaneously, the content of $\mathrm{Cu}$ in the soaking solution were determined by by inductively coupled plasma mass spectrometry (ICP, IRIS 1000, Thermo Electron Corporation, Waltham, MA, USA) and the release content of $\mathrm{Cu}$ in vitro was obtained.

\section{Cell adhesion}

Rat bone mesenchymal stem cells (rBMSCs) (ATCC; Chinese Academy of Sciences, Shanghai, China) were cultured in Dulbecco's Modified Eagle's Medium (DMEM, Gibco, USA) equipped with 10\% fetal bovine serum (FBS) plus 1\% (v/v) Penicillin-Streptomycin solution (Gibco, Life Technologies, USA) at $37{ }^{\circ} \mathrm{C}$ and $\mathrm{CO}_{2}$ $5 \%$ in a humidified atmosphere. Cells were incubated in $25 \mathrm{~cm}^{2}$ flasks to reach $80 \%$ confluence and then separated for further experiments. Different Cu-doped n-CDHA/ MAC composite scaffold samples with the size of $\varphi 6 \times 2 \mathrm{~mm}$ were used for cell experiments, and tissue culture plate (TCP) was used as a control. These samples were sterilized by ethylene oxide gas.

To investigate cell adhesion on the scaffolds, $1 \mathrm{ml}$ rBMSCs suspension with a density of $8 \times 10^{4}$ cells $/ \mathrm{ml}$ were seeded onto $\mathrm{Cu}$-doped scaffolds and located in 24well TCPs. The cells and samples were cultured at $37{ }^{\circ} \mathrm{C}$ and a humidified $5 \% \mathrm{CO}_{2}$ atmosphere for 1 and 4 days, after washing for three times with PBS, cells and samples were fixed in $4 \%$ glutaraldehyde for $24 \mathrm{~h}$. The specimens were then dehydrated in ascending concentrations of ethanol for $15 \mathrm{~min}$. Later, the samples were critical point dried, and the morphology of the cells at 1 and 4 days was shown using SEM (Hitachi S-450, Japan). 


\section{Cell viability}

BMSC proliferation was assessed by cell counting kit 8 (CCK8, KeyGEN BioTECH, Nanjing, China) following the manufactory's instructions. Briefly, the cells were attached to the wall after cultivating for $24 \mathrm{~h}$. Then the medium was added material leaching solution (preparation of the material leaching solution: the materials were immersed in the culture medium for $48 \mathrm{~h}$ under the environment of $37^{\circ} \mathrm{C}$, and then the medium was filtered through filter membrane with diameter of 0.22 micron to obtain it). The medium used by the blank control group was kept unchanged. And the medium was changed every 2 days. Add $10 \mu 1$ CCK 8 into the wells after cultivating $1,4,7$ days and cultivate for $2 \mathrm{~h}$ at $37^{\circ} \mathrm{C}, 5 \%(\mathrm{~V} / \mathrm{V})$ thermostatic cultivation in $\mathrm{CO}_{2}$ saturated humidity. The absorbance was measured at $450 \mathrm{~nm}$ using a microplate reader (Multiskan MK3, Thermo Electron Corporation, Waltham, MA, USA).

\section{Alkaline phosphatase activity}

For osteogenic differentiation of rBMSCs, cells were cultured in osteogenic medium (basal medium additionally provided with $10 \mathrm{mM} \beta$-glycerophosphate, $50 \mu \mathrm{g} / \mathrm{mL}$ ascorbic acid and $100 \mathrm{nM}$ dexamethasone). And rBMSCs were seeded on the scaffold samples and alkaline phosphatase (ALP) activity of cells was measured at 1, 4 and 7 days to evaluate the effect of $\mathrm{Cu}$-doped n-CDHA/MAC on the early osteogenic differentiation. Medium was changed up every two days. Briefly, we aspirated the culture medium, added $200 \mu \mathrm{l}$ of $1 \%$ Nonidet $P-40$ (NP-40) solution to each well and incubated for $1 \mathrm{~h}$ at $37^{\circ} \mathrm{C}$. After the cell lysate was centrifuged, $50 \mu \mathrm{l}$ supernatant was added to 96 -well plates. $50 \mu \mathrm{l}$, $2 \mathrm{mg} / \mathrm{ml} P$-nitrophenyl phosphate (Sangon, Shanghai, China) substrate solution including $0.1 \mathrm{~mol} / \mathrm{L}$ glycine and $1 \mathrm{mmol} / \mathrm{L}$ $\mathrm{MgCl} 2 \cdot 6 \mathrm{H} 2 \mathrm{O}$ was added and incubated for $30 \mathrm{~min}$ at $37^{\circ} \mathrm{C}$. At last, we added $100 \mu \mathrm{l} 0.1 \mathrm{~N} \mathrm{NaOH}$ to quench the reaction. The absorbance of ALP at $\lambda=405 \mathrm{~nm}$ was quantified on a microplate reader (SPECTRAmax 384, Molecular Devices, USA). The total protein content was measured by the bicinchoninic acid protein assay kit (Pierce Biotechnology Inc, Rockford, IL). The absorbance was read at $\lambda=405 \mathrm{~nm}$ and the total protein was estimated. The ALP levels were obtained as the changed OD values and normalized to the total protein content.

\section{Animal experiment}

The animal experiments were carried out in Sichuan University and the protocol was approved by the Biomedical Ethics Committee of West China Hospital,
Sichuan University (2017046A). During the whole animal experiments, laboratory animal guideline for ethical review of animal welfare for the animal was followed according to National Standard of China. 11 mature New zealand white rabbits $(2.0-2.5 \mathrm{~kg})$ were operated to confirm the role of scaffolds in bone repair. After skin preparation and anesthesia, a $2 \mathrm{~cm}$ incision in the lateral distal femur was performed to expose the femoral condyle. A cavitary defect of $4 \mathrm{~mm}$ in diameter and $8 \mathrm{~mm}$ in depth was made by special bone drill. Saline irrigation was used to wash the wounds, the blank group, $0 \% \mathrm{Cu}-$ doped and 1\% Cu-doped n-CDHA/MAC composite scaffolds were implanted into the bone defects. To prevent infection, each rabbit received penicillin intramuscularly $10,000 \mathrm{U} / \mathrm{kg}$, one preoperative dose and two postoperative doses. At 4,8 and 12 weeks after surgery, the animals were sacrificed by injecting overdose anesthetics and the samples were utilized for imaging examinations and histological analysis.

To observe the process of bone formation and degradation of scaffolds, some samples were examined using X-ray radiograph at 4,8 and 12 weeks after implantation.

After 4, 8 and 12 weeks, the rabbits were sacrificed for histological analysis. The implants were harvested and immediately fixed in $10 \%$ buffered formaldehyde solution for one week. After that, the samples were decalcified for one month and embedded in paraffin. Thin sections were made and then stained with routine Hematoxylin and eosin (HE) staining.

\section{Statistical analysis}

Data are presented as mean \pm SD. Statistical difference was analyzed using one-way analysis of variance and Tukey's multiple comparison tests. A value of $P<0.05$ was considered to be statistically significant.

\section{Results}

\section{Physicochemical characteristics of composite scaffolds}

The morphology of Cu-doped n-CDHA/MAC composite scaffold was observed by Micro-CT. It was found that the composite scaffolds showed densely distributed macropores with the diameter from $100 \mu \mathrm{m}$ to $500 \mu \mathrm{m}$. And the macropores were interconnected by little pores located in the walls of macropores (Figure 2).

The total porosity changed little along with different ratio of $\mathrm{Cu}$ (Table 1). It could also been found that the compressive strength of Cu-doped n-CDHA/MAC 

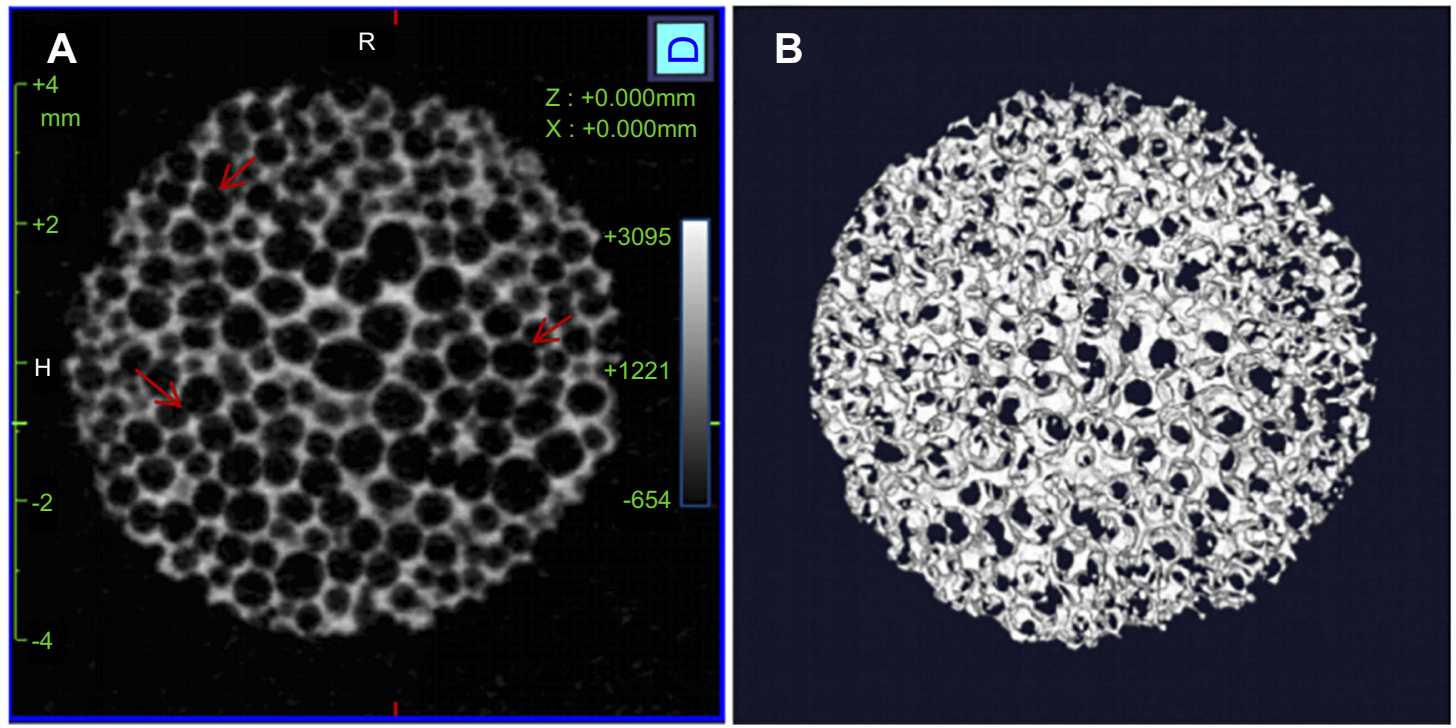

Figure 2 Micro-CT images of $1 \%$ Cu-doped n-CDHA/MAC with porosity of $81 \%$. (A) cross-section of scaffold; (B) three-dimensional reconstruction of scaffold. The red arrow represents the interconnected pores located in the walls of macropores.

Abbreviations: n-CDHA/MAC, nano calcium-defcient hydroxyapatite/multi(amino acid) copolymer.

Table I Total porosity, compressive strength and concentration of $\mathrm{Cu}$ in scaffolds of Cu-doped n-CDHA/MAC composite scaffolds

\begin{tabular}{|l|l|l|l|l|l|}
\hline & $\begin{array}{l}\text { 0\% Cu-doped } \\
\text { n-CDHA/MAC }\end{array}$ & $\begin{array}{l}\text { 0.5\% Cu-doped } \\
\text { n-CDHA/MAC }\end{array}$ & $\begin{array}{l}\text { I \% Cu-doped } \\
\text { n-CDHA/MAC }\end{array}$ & $\begin{array}{l}\text { 2\% Cu-doped } \\
\text { n-CDHA/MAC }\end{array}$ & $\begin{array}{l}\text { 5\% Cu-doped } \\
\text { n-CDHA/MAC }\end{array}$ \\
\hline Total porosity(\%) & $8 I \pm 3$ & $82 \pm 3$ & $82 \pm 3$ & $8 I \pm 2$ & $81 \pm 4$ \\
Compressive strength(MPa) & $12 \pm 1$ & $12 \pm 1$ & $12 \pm 2$ & $11 \pm 1$ & $12 \pm 1$ \\
Cu in scaffolds & - & $(0.49 \pm 0.01) \%$ & $(0.96 \pm 0.02) \%$ & $(1.92 \pm 0.01) \%$ & $(4.87 \pm 0.02) \%$ \\
\hline
\end{tabular}

Abbreviations: n-CDHA/MAC, nano calcium-defcient hydroxyapatite/multi(amino acid) copolymer.

composite scaffolds almost keep the same regardless of the variation of $\mathrm{Cu}$ concentration (Table 1). Besides, the concentrations of $\mathrm{Cu}$ in scaffolds were also shown in Table 1.

\section{Weight loss of scaffolds in PBS}

It also showed the weight loss of different $\mathrm{Cu}$-doped n-CDHA/MAC composite scaffolds soaked in PBS over time. The total weight loss of samples increased in PBS with time, demonstrating that the composite scaffolds were degradable. Moreover, for different $\mathrm{Cu}$-doped scaffolds, it was demonstrated that they showed similar degradation rate, indicating that $\mathrm{Cu}$ in composite had little influence on scaffolds. Also, the composite scaffolds exhibited high degradation rate at the first 4 weeks with weight loss greater than $8 \%$ every week, and then gradually decreased. At the end of the test, the overall degradation of material (weight loss) reached almost $63 \%$ (Figure 3). During the the whole process, all samples were gradually degraded and no collapse of samples were observed visually, indicating the samples could maintain its strength during degradation and meet the requirement of mechanical support for bone regeneration.

\section{Cu release of scaffolds in PBS}

$\mathrm{Cu}$ release of different scaffolds were obtained. The concentrations of $\mathrm{Cu}$ in PBS increased with the increase of $\mathrm{Cu}$ in the scaffolds. And it was also found that the contents of $\mathrm{Cu}$ released from scaffolds decreased with time, indicating the consistent tendency with the weight loss of scaffolds. The composite scaffolds showed high $\mathrm{Cu}$ release at the first 4 weeks and then gradually decreased. After soaking 1, 2, 4, 8, 12 and 16 weeks, the concentrations of $\mathrm{Cu}$ of $0.5 \% \mathrm{Cu}$-doped n-CDHA/MAC were $1.6 \mathrm{ppm}, 1.3 \mathrm{ppm}, 1.1 \mathrm{ppm}, 0.9 \mathrm{ppm}$, $0.3 \mathrm{ppm}$ and $0 \mathrm{ppm}$, respectively. The concentrations of $\mathrm{Cu}$ of 1\% Cu-doped n-CDHA/MAC were 2.3 ppm, 2.5 ppm, 2.1 ppm, $1.5 \mathrm{ppm}, 0.9 \mathrm{ppm}$ and $0.4 \mathrm{ppm}$, respectively. The concentrations of $\mathrm{Cu}$ of $2 \% \mathrm{Cu}$-doped n-CDHA/MAC were 5 ppm, 4.3 ppm, 4.1 ppm, 3.6 ppm, 1.8 ppm and 0.9 ppm, respectively. And the concentrations of $\mathrm{Cu}$ of $5 \% \mathrm{Cu}$-doped 


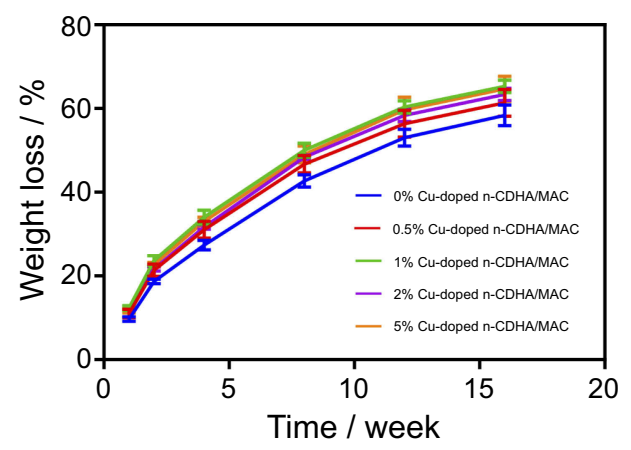

Figure 3 Weight loss of n-CDHA/MAC composite scaffolds with different concentration of $\mathrm{Cu}$ after immersing in PBS over time.

Abbreviations: $n-C D H A / M A C$, nano calcium-defcient hydroxyapatite/multi(amino acid) copolymer; PBS, phosphatic buffer solution.

n-CDHA/MAC were 11.5 ppm, 11 ppm, 10.5 ppm, 9.6 ppm, $5.9 \mathrm{ppm}$ and $2.2 \mathrm{ppm}$, respectively (Figure 4). It could be seen that the release of $\mathrm{Cu}$ from the scaffolds into PBS showed a marked dependence on the weight loss and initial amount of $\mathrm{Cu}$ in the scaffolds.

\section{Cell adhesion and proliferation}

SEMs of rBMSCs attached on the surfaces of $\mathrm{Cu}$-doped n-CDHA/MAC composite scaffolds were performed at 1 and 4 days (Figure 5). It was found that the cells attached well to the scaffold surfaces and the cells were well spread on the surfaces of scaffolds after cultivating for 1 days. Besides, the cells also developed pseudopods, forming close attachment between the cells and scaffold surfaces. $1 \% \mathrm{Cu}$-doped $\mathrm{n}$-CDHA/MAC showed the best cell adhesion with more pseudopods, indicating the best cytocompatibility of $1 \% \mathrm{Cu}$-doped composite scaffold. At 4 days, it was shown that cells attached to the composite scaffolds increased. the cells spread out and formed a cellular layer with close attachment to the scaffold surfaces. And more

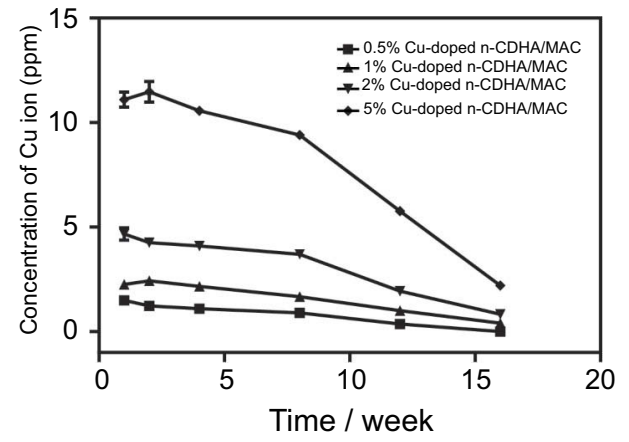

Figure $4 \mathrm{Cu}$ release curve of different Cu-doped n-CDHA/MAC scaffolds in PBS. Abbreviations: $n-C D H A / M A C$, nano calcium-defcient hydroxyapatite/multi(amino acid) copolymer; PBS, phosphatic buffer solution. cells could be found attached on $1 \% \mathrm{Cu}$-doped composite scaffold surface. And it was demonstrated that $\mathrm{Cu}$ could promote cell adhesion and enhance the biological properties of composites.

The CCK8 was conducted to continuously measure the proliferation of rBMSCs cultured on different $\mathrm{Cu}$-doped scaffolds at 1, 4 and 7 days because optimal density (OD) values could act as a direct indicator for cell proliferation on scaffolds. A gradually increasing tendency of cell proliferation in a timedependent manner was found in each group, although there was no statistically difference in proliferation rate at 1 day. After cultivating for 4 days, obvious differences were found in experimental group compared to control group $(P<0.05$, respectively). The $0 \%, 0.5 \%$ and $1 \% \mathrm{Cu}$-doped group showed superior proliferation to control group, while $2 \%$ and $5 \% \mathrm{Cu}-$ doped group presented inferior proliferation to control group. And at 7 days, the differences were still obvious and statistically significant differences were also found in $0.5 \%, 1 \%, 2 \%$ and 5\% compared to control group ( $P<0.05$, respectively) (Figure 6). For 1\% Cu-doped group, the most significant increase was observed compared to other groups. Also, for $2 \%$ and $5 \% \mathrm{Cu}$-doped group, it showed a conspicuous decrease compared to control group, which indicated cytotoxicity to the rBMSCs. So, these results confirmed the optimal $\mathrm{Cu}$-doped $\mathrm{n}$-CDHA/MAC to promote cell proliferation was $1 \%$ in mass ratio and when this ratio was more than $2 \%$, it would show toxic effects to rBMSCs.

\section{ALP activity}

ALP is a specific indicator of osteogenic differentiation. ALP activity of rBMSCs cultured on the composite scaffolds was assessed at 1, 4 and 7 days. The ALP activity increased with the extension of time for five different composite scaffolds. Statistically difference was found in $1 \% \mathrm{Cu}$-doped group compared to $0 \% \mathrm{Cu}$-doped group after cultivating for 1 day $(P=0.04)$. Moreover, at 4 days, obvious difference was found in $1 \%, 2 \%$ and $5 \% \mathrm{Cu}$-doped groups compared to $0 \% \mathrm{Cu}-$ doped group $(P<0.001, P=0.012$ and $P=0.001$, respectively). And at 7 days, the differences became more obvious and statistically significant differences were found among groups (Figure 7). For 1\% Cu-doped group, a significant increase was observed compared to $0 \% \mathrm{Cu}$-doped group. Also, for $2 \%$ and $5 \% \mathrm{Cu}$-doped group, it showed an obvious decrease compared to $0 \% \mathrm{Cu}$-doped group. All tested scaffolds containing $\mathrm{Cu}$ ranged from $0 \%$ to $1 \%$ of $n-\mathrm{CDHA} /$ MAC showed an increased mineralization of the cells, indicating that the scaffolds with proper content of $\mathrm{Cu}$ can stimulate the osteoblastic differentiation of rBMSCs. 


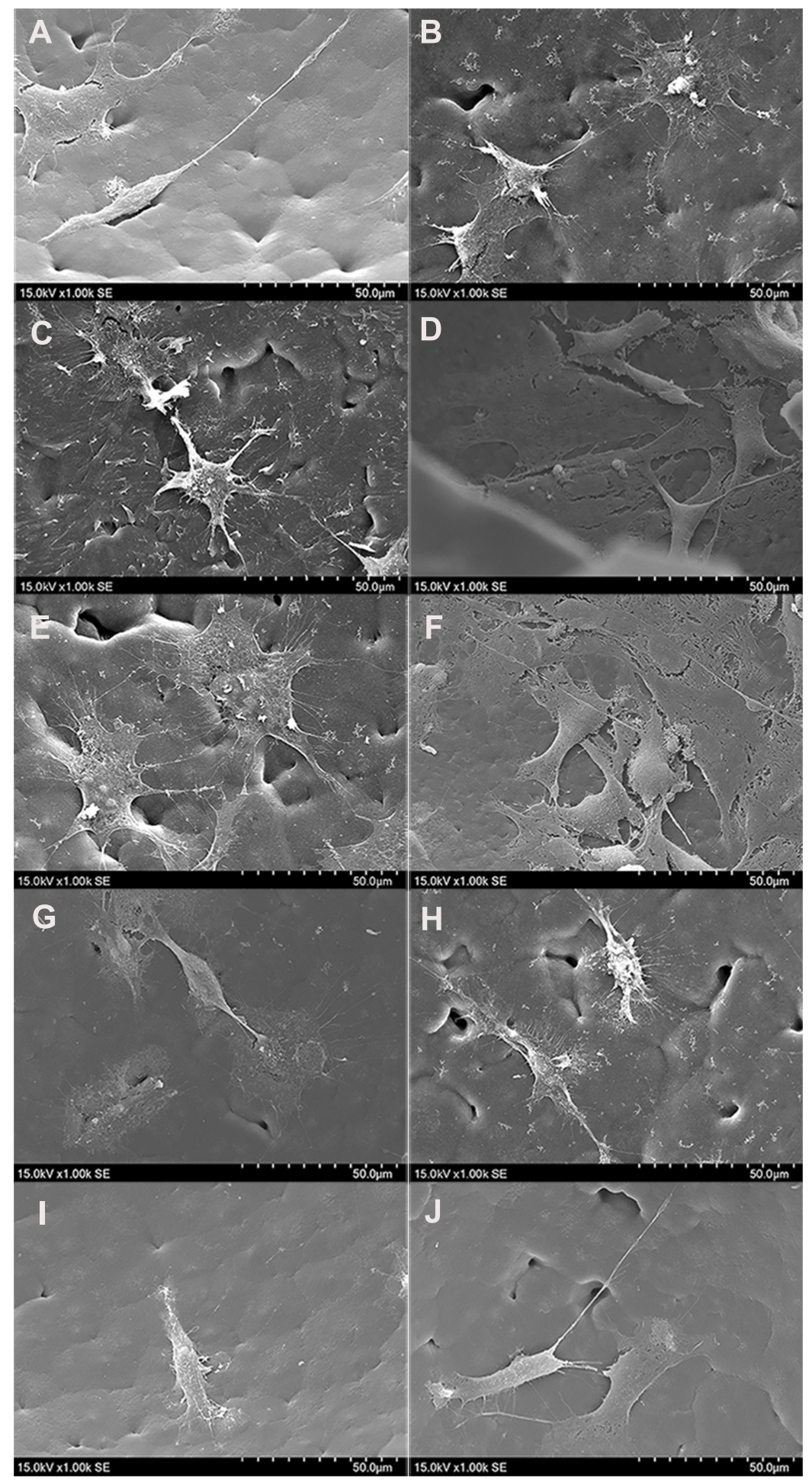

Figure 5 SEM micrographs of rat BMSCs cells attachment on the surfaces of Cu-doped n-CDHA/MAC composite scaffolds after I days (A, C, E, G, I) and 4 days (B, D, F, H, J) of culture. (A and B), 0\% Cu-doped n-CDHA/MAC; (C and D), 0.5\% Cu-doped n-CDHA/MAC; (E and F), 1\% Cu-doped n-CDHA/MAC; (G and $\mathbf{H}), 2 \%$ Cu-doped n-CDHA/MAC; (I and J), 5\% Cu-doped n-CDHA/MAC.

Abbreviations: n-CDHA/MAC, nano calcium-defcient hydroxyapatite/multi(amino acid) copolymer; SEM, scanning electron microscopy; BMSCs, bone marrow stromal cells.

\section{Scaffolds implanted in vivo}

After obtaining X-ray radiographs of distal part of femurs in which the scaffolds implanted, it was found that there was a large bone cavity for blank group and little osteosclerosis formation around the margin in the radiographs of 4-week post-implantation (Figure 8A), while closely connection 


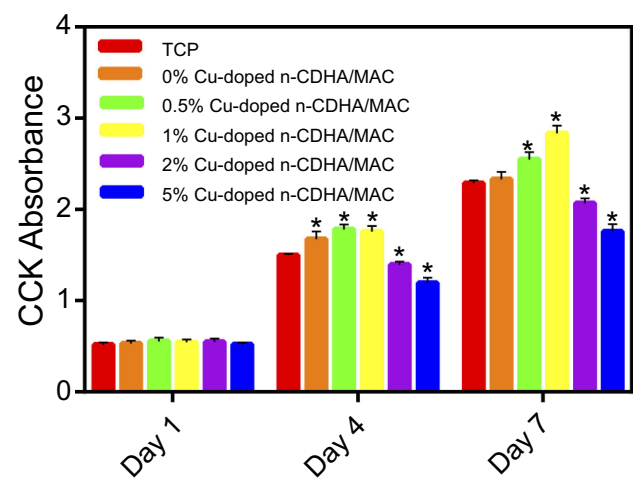

Figure $6 \mathrm{CCK}$ assay showing the cell growth of rat BMSCs cultured with different Cu-doped n-CDHA/MAC composite scaffolds at dayl, day 4 and day 7. * means significant difference between Cu-doped groups and control group (TCP) $(p<0.05)$. Abbreviations: CCK, cell count kit; BMSCs, bone marrow stromal cells; TCP, tissue culture plate; n-CDHA/MAC, nano calcium-defcient hydroxyapatite/multi (amino acid) copolymer.

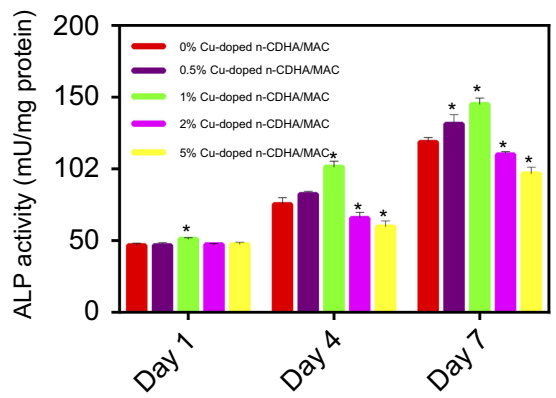

Figure 7 ALP activity of rat BMSCs cultured on different Cu-doped n-CDHA/MAC composite scaffolds at day I, day 4 and day $7 . *$ means significant difference between Cu-doped groups and $0 \% \mathrm{Cu}$-doped group $(p<0.05)$.

Abbreviations: ALP, alkaline phosphatase; BMSCs, bone marrow stromal cells; n-CDHA/MAC, nano calcium-defcient hydroxyapatite/multi(amino acid) copolymer.

between the scaffold and the new bone formation around the scaffold in 1\% Cu-doped group (Figure 8D). At 8 weeks after implantation, there were a reduction of the bone cavity and osteosclerosis formation for the blank group (Figure 8B), while degradation of the composite scaffold and new bone formation occupying the cavity for the $1 \% \mathrm{Cu}$-doped group were observed (Figure 8E). At 12 weeks post-implantation, more osteosclerosis formation and visible boundary of the osteosclerosis for blank group were observed (Figure 8C), while the more markedly degradative scaffold was wrapped by newly regenerated bone completely and no clear boundary was found between bone and scaffold (Figure 8F). The $\mathrm{X}$-ray scanning of bone after implantation demonstrated the ability of degradation and osteogenesis of the composite scaffolds.

H\&E staining of $0 \%$ and $1 \% \mathrm{Cu}$-doped scaffolds implantation in the bone were observed. At 4 weeks after operation, there were some inflammatory cells in the macropores of the composite scaffolds and a few new bone formation. Also, it could be found that more blood vessel formation in $1 \% \mathrm{Cu}-$ doped scaffolds (Figure 9A and D). At 8 weeks after surgery, inflammatory cells disappeared. more newly regenerated bone tissues were stored in the macropores of scaffolds and active osteoblasts emerged. The amount of bone matrix formed in macropores increased markedly. Blood vessels were found in $0 \% \mathrm{Cu}$-doped group, while there was more visible increase of blood vessels in $1 \% \mathrm{Cu}$-doped group (Figure 9B and E). At 12 weeks after surgery, the macropores of composite scaffolds were almost completely encapsulated by newly formed bone. And osteoblast-like cells could be seen around the bone (Figure 9C and F). At three different time points, it was found that more new blood vessels formation and bone regeneration in the macropores of $1 \%$ $\mathrm{Cu}$-doped group compared to $0 \% \mathrm{Cu}$-doped group.

\section{Discussion}

ONFH is a potentially devastating disease characterized by physiopathologic mechanism of circulation interruption and progressive osteonecrosis. Currently, there are rare effective methods to cure the early-stage ONFH and delay the time performing THA. According to Tan's research, ${ }^{27}$ ischemia of the femoral head and decreased differentiation of BMSC are the significant reasons resulting in the occurrence and development of ONFH. However, all of the present methods can't effectively repair ONFH and avoid the collapse of joint surface. So, based on the characteristics of ONFH, Promising composite scaffolds must be equipped with eligible biocompatibility, Three-dimensional porous structure and appropriate mechanical strength to enhance bone ingrowth and provide structural support. ${ }^{28,29}$ Besides, studies have reported doping $\mathrm{Cu}$ into biomaterials can enhance their original angiogenesis and osteogenesis properties. ${ }^{20}$ So, we combined the osteogenesis of n-CDHA/MAC and angiogenesis of $\mathrm{Cu}$ to synthesize the novel composite scaffolds. In this study, the results preliminarily revealed the biosecurity of Cu-doped n-CDHA/MAC composite scaffolds and the optimal concentration of $\mathrm{Cu}$ to promote angiogenesis and osteogenesis.

Studies have shown that the composite scaffold with macropore size at least $100 \mathrm{um}$ and porosity exceeding $70 \%$ facilitated cell ingrowth and mineralized bone regeneration. ${ }^{22}$ And the compressive strength of cancellous bone of human being was 2-25 $\mathrm{MPa}$. Our results indicated that the macropores shows uniform diameters, which were similar to the fundamental requirements. 

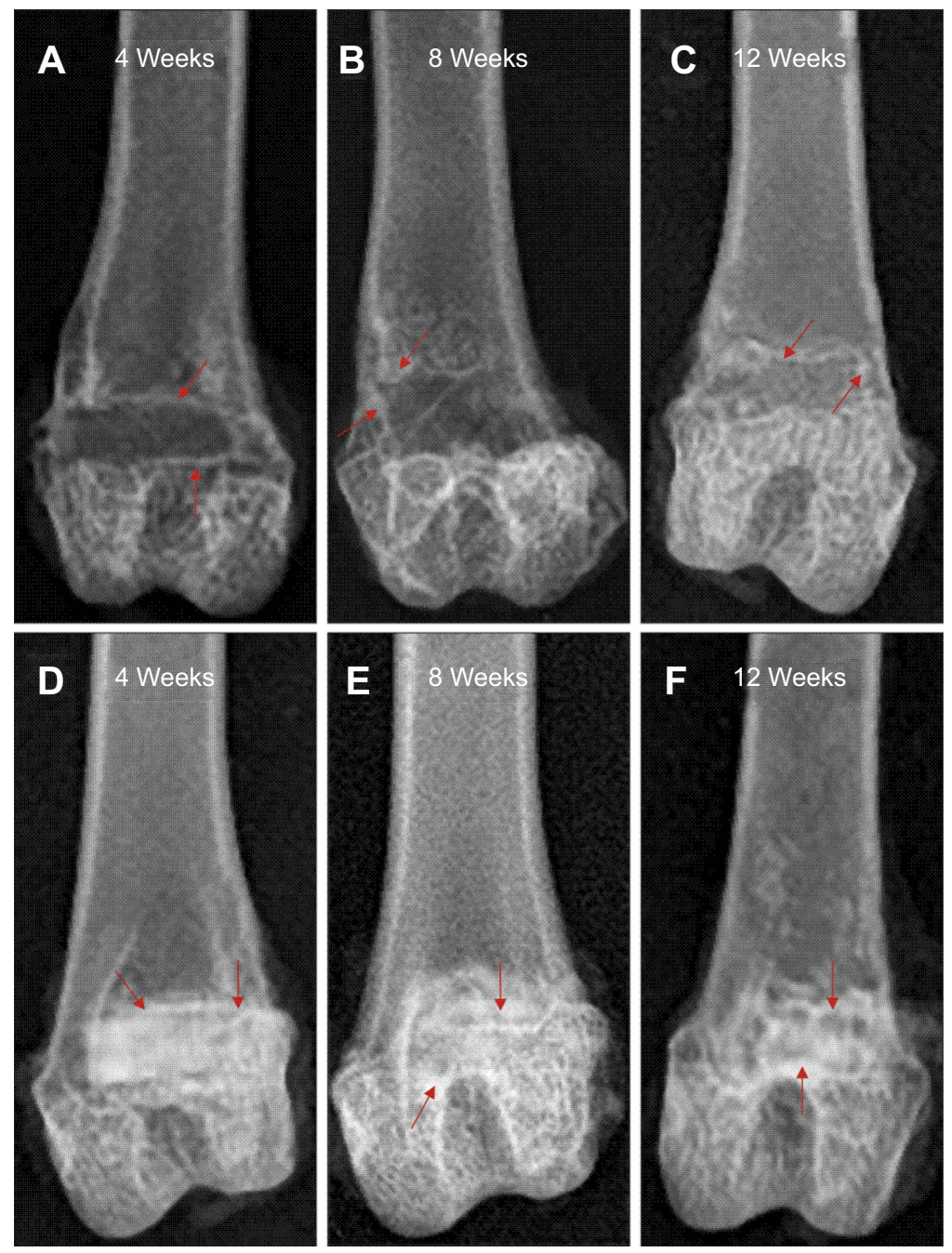

Figure 8 X-ray images revealing the repair of bone defects in blank group and I\% Cu-doped n-CDHA/MAC group at postoperative 4, 8 , and I2 weeks: (A, B and C) blank group; (D, E and F) I\% Cu-doped n-CDHA/MAC group. (A and D), 4 weeks; (B and E), 8 weeks; (C and F), 12 weeks. The red arrow represents new bone formation in bone defect.

Abbreviations: n-CDHA/MAC, nano calcium-defcient hydroxyapatite/multi(amino acid) copolymer.

Moreover, doping n-CDHA/MAC with different mass ratio of $\mathrm{Cu}$ had little influence on the total porosity and compressive strength. Obviously, our prepared composite scaffolds were equipped with porous structure (approximate $81 \%$ ) and suitable mechanical strength (approximate $12 \mathrm{MPa}$ ), which can be used for defect repair.

Appropriate degradation rate of scaffold and nontoxic degradation product are important for outstanding scaffolds. And it is commonly believed that bioactive scaffolds placed in vivo with a suitable degradation rate can provide the space for matrix deposition and bone ingrowth until osteogenesis was finished. ${ }^{30}$ In our study, the overall degradation of the scaffold (weight loss) reached almost $63 \%$ at the end of the test. And the porous structure of the scaffold has a larger surface area in contact with the immersion solution at the initial immersion, so the degradation rate is faster. During the degradation process, the amorphous part of the scaffolds degraded earlier than the crystalline part, and the degradation rate was faster. This is another factor in the early degradation of scaffolds. Furthermore, the degradation products include hydroxyapatite, different amino acids and calcium sulfate, which are not only nontoxic for the living body, but also can function as the materials of bone formation.

$\mathrm{Cu}$ can enhance angiogenesis and osteogenesis properties of the scaffolds via slow-release from the biomaterials with the advantage of low cost, high stability and potentially greater safety. ${ }^{20}$ The mechanism is that $\mathrm{Cu}$ can promote the expression of hypoxia-inducing factor-1 (HIF-1) to stimulate the secretion of VEGF, which is 

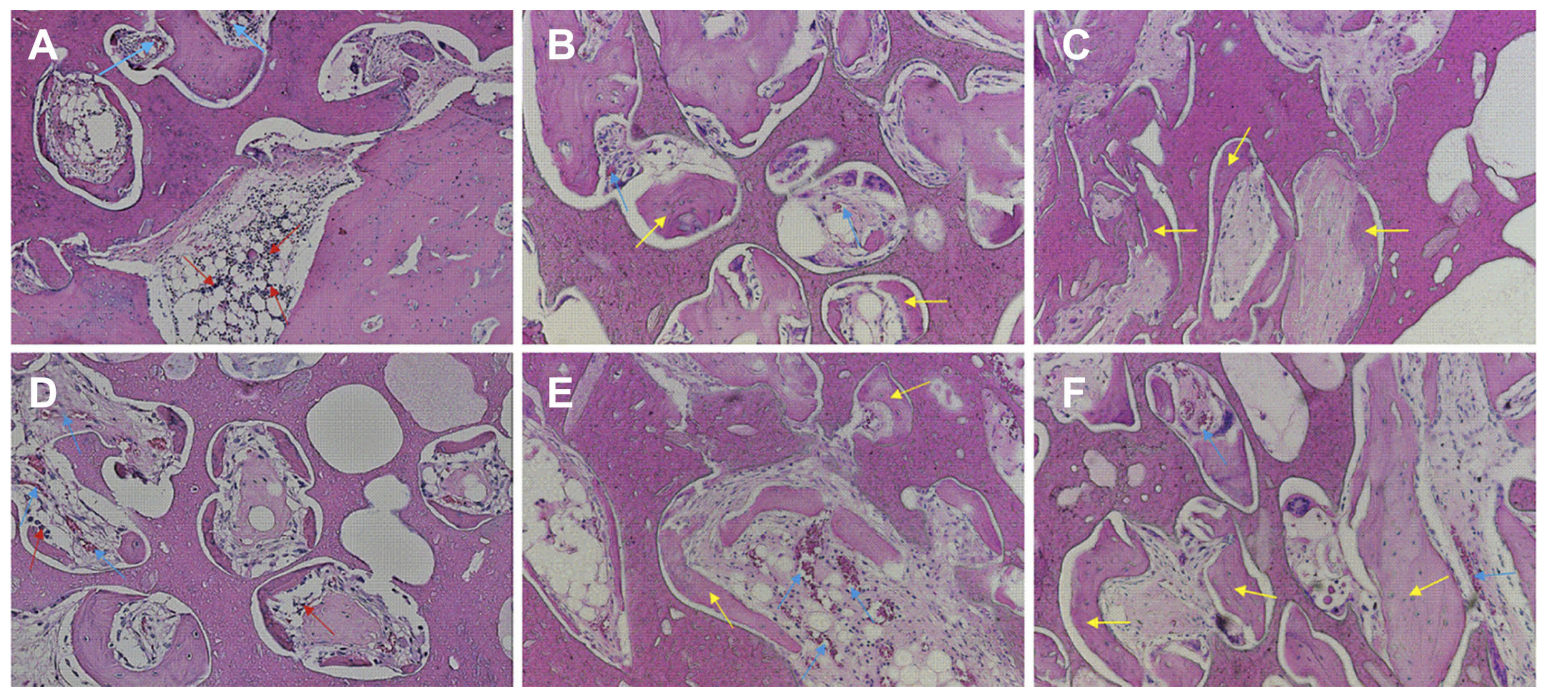

Figure 9 HE staining of n-CDHA/MAC composite scaffolds (A, B and C) and I\% Cu-doped n-CDHA/MAC composite scaffolds (D, E and F) harvested at postoperative 4, 8 , and 12 weeks (magnification 40x). (A and D), 4 weeks; (B and E), 8 weeks; ( $C$ and F), 12 weeks. The red arrow represents inflammatory cells. The blue arrow represents blood vessel. And yellow arrow represents bone matrix in macropores.

Abbreviations: HE, hematoxylin and eosin; n-CDHA/MAC, nano calcium-defcient hydroxyapatite/multi(amino acid) copolymer.

identified as the critical factor having the strongest biological action in inducing vascularization. ${ }^{20,31}$ However, high concentrations of ions can lead to cytotoxicity. ${ }^{32}$ And there is no consensus on the threshold for toxic effects of $\mathrm{Cu}$. From the study of Burghardt, ${ }^{33}$ they believed that the threshold for toxic effects of $\mathrm{Cu}$ on MSC was $0.5 \mathrm{mM}$. Bejarano ${ }^{34}$ doped $\mathrm{Cu}$ in silicate bioactive glasses and came to a conclusion that the cytotoxicity threshold of $\mathrm{Cu}$ was $3.0 \mathrm{ppm}$, while some researcher reported the effective $\mathrm{Cu}$ concentration enhancing vascularization was $14-57 \mathrm{ppm}^{20}$ And the study has demonstrated that human umbilical vein endothelial cells (HUVECs) were stimulated to proliferation, if the $\mathrm{Cu}$ concentration in culture medium was less than $32 \mathrm{ppm}^{35}$ Possibly, different experimental conditions and different kinds of cells used in vitro experiments might explain these results. Besides, the release of metal ions is determined by the initial dose doped in scaffolds and the degradation rate of the scaffolds. In our study, the release of $\mathrm{Cu}$ was consistent with the initial dose of $\mathrm{Cu}$ and degradation curve of scaffolds, indicating the initial dose of $\mathrm{Cu}$ and the rate of degradation determined the release rate. During the degradation process, there was no collapse of the scaffold observed, so no burst release of $\mathrm{Cu}$ was observed. Noteworthy, the slow and sustained release of $\mathrm{Cu}$ is possibly favourable for tissue engineering applications.

To investigate the cytocompatibility of the $\mathrm{Cu}$-doped n-CDHA/MAC scaffolds in vitro, the rBMSCs were used to cultivate with scaffolds. The cell adhesion was observed by SEM and the proliferation of cells was determined with CCK assay at different time points. As described in literature, ${ }^{36}$ Adhesion is the first step of cell-material interaction, which play a key role in cell functions including proliferation and differentiation. Our results indicated that $1 \% \mathrm{Cu}$-doped $\mathrm{n}-\mathrm{CDHA} / \mathrm{MAC}$ composite scaffold showed better cell adhesion compared to other groups. Also, further analyses of the survival of rBMSCs were done by CCK to determine the proliferation cells cultivated with scaffolds. It concluded that obviously positive effects on cell proliferation were observed with the concentration of $\mathrm{Cu}$ ranging from 0 to $1 \%$, while more than $2 \%$ showed inhibited effects on cell proliferation compared to control group. Based on these results, we considered that the optimal concentration to promote rBMSCs proliferation was $1 \%$ of the scaffolds in mass ratio and the threshold for toxic effects of $\mathrm{Cu}$ on rBMSCs was $2 \%$.

$\mathrm{Cu}$ is a vital component of many proteins such as cytochrome oxidase and superoxide dismutase, which act as essential roles in cell activity, ${ }^{35} \mathrm{But}$ excess $\mathrm{Cu}$ is toxic. The cytotoxicity of $\mathrm{Cu}$ was identified as the production of free hydroxyl radicals, which could participate in the disruption of membranes and organelles by inactivating essential enzymes. ${ }^{37}$ On the other hand, proper supplementary of $\mathrm{Cu}$ facilitates proliferation of cells on composite scaffold. Furthermore, Ewald et al has demonstrated that $\mathrm{Cu}$ enhances cell activity and proliferation of osteoblastic 
cells on brushite scaffold. ${ }^{38}$ And they also indicated that $\mathrm{Cu}$ promoted the expression of several proteins for bone formation including bone sialoprotein (BSP), which could stimulates adhesion, migration and survival of cells in vitro. Therefore, proper content of $\mathrm{Cu}$ promote cell adhesion and proliferation.

ALP, as a marker of osteogenic differentiation of stem cells, was secreted by osteoblasts. ${ }^{39}$ So, ALP expression can reveal the osteogenic differentiation of rBMSCs. In our study, higher level of ALP expression in $0.5 \%$ and $1 \%$ groups were found than in $0 \%, 2 \%$ and $5 \%$ groups at 7 days, indicating that the cell differentiation was quicker after being cultured on the composite with $\mathrm{Cu}$ ranging from $0 \%$ to $1 \%$ than other groups. Moreover, it was also demonstrated that a negative cell differentiation on scaffolds with $\mathrm{Cu}$ ranging from $2 \%$ to $5 \%$ compare to $0 \%$ group, showing the inhibition effect on cell differentiation when $\mathrm{Cu}$ content was more than $2 \%$. Accordingly, the n-CDHA/MAC scaffolds with contents of $\mathrm{Cu}$ ranging from $0 \%$ to $1 \%$ showed superior ALP activity compared to that with no $\mathrm{Cu}$.

Similarly, superabundant dose of $\mathrm{Cu}$ influences BMSCs differentiation due to the disturbance of cell activity like what mentioned above. Many scholars has reported that $\mathrm{Cu}$-doped composites could enhance the bone-related gene expressions such as ALP, osteopontin (OPN) and Runx $2 .{ }^{33,38,40,41}$ However, few studies illustrated the relevant mechanism of $\mathrm{Cu}$ stimulating osteogenesis. It was demonstrated that $\mathrm{Cu}$ could promote the expression of HIF-1 and initiate the transcription of hypoxia-related genes such as VEGF. Then, activation of VEGF receptors resulted in the expression of genes including Runx2, Bone Morphogenetic Protein (BMP) and OPN, which are stimulating factors of osteogenesis. ${ }^{42,43}$ This might account for stimulation of cell differentiation.

The in vitro experiments proved that $1 \% \mathrm{Cu}$-doped n-CDHA/MAC promoted the proliferation and differentiation of rBMSCs, indicating a good potential to induce bone formation. We used an in vivo model to investigate the degradation property, as well as the osteogenic and angiogenic capability. The scaffolds with a suitable degradation rate placed in vivo can provide the space for matrix deposition and tissue ingrowth until healing was finished. ${ }^{30}$ The $\mathrm{X}$-ray imaging of $1 \% \mathrm{Cu}$-doped group at 4, 8, 12 weeks showed the capacity of degradation and osteogenesis compared to blank group, which was similar to the results of the experiments in vitro. $\mathrm{H} \& \mathrm{E}$ staining of $1 \% \mathrm{Cu}$-doped group showed osteoblast-like cells beading at the interface between bone and scaffolds, obvious new bone formation and bone ingrowth into macropores of the scaffolds, together with more blood vessels formation compared to $0 \% \mathrm{Cu}$-doped group, indicating that $\mathrm{Cu}$ in the scaffolds resulted in superior osteogenesis and angiogenesis. ${ }^{16-18,20,33}$ Because deficiencies in oxygen and nutrient exchange at the necrotic area are a major issue due to lack of vascularization. So, adequate blood supply is the prerequisite for formation of bone and osteogenesis will vary according to the vascularization of the site. ${ }^{44}$ Highly expressed factors mentioned above synergistically recruit stem cells and endothelial cells into bone defects to enhance vascularization and promote osteogenesis. Thus biomaterials with proper contents of $\mathrm{Cu}$ showed better osteogenesis and angiogenesis in vivo than that with no $\mathrm{Cu}$. And our study came to the analogous conclusion: $\mathrm{Cu}$-doped n-CDHA/MAC composite scaffolds with the contents of $\mathrm{Cu} 1 \%$ exhibited outstanding angiogenesis and osteogenesis.

This study has preliminarily demonstrated $\mathrm{Cu}$-doped n-CDHA/MAC was equipped with properities of osteogenesis and angiogenesis. And we will future investigate the mechanism of osteogenesis and angiogenesis of the composite scaffolds.

\section{Conclusion}

In this study, $\mathrm{Cu}$-doped n-CDHA/MAC composite scaffolds were prepared. $\mathrm{Cu}$-doped n-CDHA/MAC scaffolds were degradable and showed satisfactory mechanical property (approximately $12 \mathrm{MPa}$ ). Also, the $\mathrm{Cu}$-doped scaffolds presented slow and sustained release of $\mathrm{Cu}$ and exhibited remarkable influence on the osteogenesis and angiogenesis. Compared to no $\mathrm{Cu}$-doped scaffolds, $0.5 \%$ and $1 \% \mathrm{Cu}$ doped ones showed stimulation, while $2 \%$ and $5 \%$ were demonstrated inhibitation on bone regeneration. And prepared 1\% Cu-doped n-CDHA/MAC scaffolds combined characteristics with optimal osteogenesis capacity. It was also found that the scaffolds doped $\mathrm{Cu}$ ranging from $0 \%$ to $1 \%$ in mass ratio will promote the proliferation and differentiation of rBMSCs. So, doping n-CDHA/MAC with $1 \%$ $\mathrm{Cu}$ is safe and can provide a promising approach for enhancing the capacity to heal of bone defect. This new biomedical scaffold with the properities osteogenesis and angiogenesis might be used to treat ONFH in the future.

\section{Acknowledgments}

This research was funded by the National Natural Science Foundation of China Program (81501873), Science and Technology Project of Sichuan Province (2015SZ0085). Study approval was obtained from the Biomedical Ethics 
Committee of West China Hospital, Sichuan University (2017046A). We followed laboratory animal guideline for ethical review of animal welfare for the animal according to National Standard of China during the whole animal experiments. P.M. and H.P. contributed equally to this work and should be considered as equal first authors. The data supporting the results reported in the manuscript will not be shared due to our further research on the composite scaffolds.

\section{Disclosure}

The authors report no conflicts of interests in this work.

\section{References}

1. Kubo T, Ueshima K, Saito M, Ishida M, Arai Y, Fujiwara H. Clinical and basic research on steroid-induced osteonecrosis of the femoral head in Japan. J Orthop Sci. 2016;21(4):407-413.

2. Lieberman JR, Engstrom SM, Michael Meneghini R, Nelson Fong S. Which factors influence preservation of the osteonecrotic femoral head? Cli Orthop Relat Res. 2012;470(2):525-534.

3. Marker DR, Seyler TM, Ulrich SD, Siddharth S, Mont MA. Do modern techniques improve core decompression outcomes for hip osteonecrosis? Cli Orthop Relat Res. 2008;466(5):1093-1103.

4. Chughtai M, Piuzzi NS, Khlopas A, Jones LC, Goodman SB, Mont MA. An evidence-based guide to the treatment of osteonecrosis of the femoral head. Bone Joint J. 2017;99-B(10):1267-1279.

5. Mont MA, Cherian JJ, Sierra RJ, Jones LC, Lieberman JR. Nontraumatic osteonecrosis of the femoral head: where do we stand today? A ten-year update. J Bone Joint Surg Am. 2015;97(19):1604-1627.

6. Mont MA, Ragland PS, Etienne G. Core decompression of the femoral head for osteonecrosis using percutaneous multiple small-diameter drilling. Cli Orthop Relat Res. 2004;429(429):131-138.

7. Zhao G, Yamamoto T, Iwasaki K, Yamaguchi R, Ikemura S, Iwamoto Y. Radiological outcome analyses of transtrochanteric posterior rotational osteotomy for osteonecrosis of the femoral head at a mean follow-up of 11 years. J Orthop Sci. 2013;18(2):277-283.

8. Ito H, Tanino H, Yamanaka Y, et al. Long-term results of conventional varus half-wedge proximal femoral osteotomy for the treatment of osteonecrosis of the femoral head. J Bone Joint Surg Br Volume. 2012;94(3):308.

9. Ikemura S, Yamamoto T, Jingushi S, Nakashima Y, Mawatari T, Iwamoto Y. Leg-length discrepancy after transtrochanteric curved varus osteotomy for osteonecrosis of the femoral head. J Bone Joint Surg Br. 2007;89(6):725-729.

10. Biswal S, Hazra S, Yun HH, Hur CY, Shon WY. Transtrochanteric rotational osteotomy for nontraumatic osteonecrosis of the femoral head in young adults. Clin Orthop Relat Res. 2009;467(6):1529-1537.

11. Hungerford DS. Treatment of osteonecrosis of the femoral head: everything's new. J Arthroplasty. 2007;22(4 Suppl 1):91-94.

12. Rose FR, Oreffo RO. Bone tissue engineering: hope vs hype. Biochem Biophys Res Commun. 2002;292(1):1-7. doi:10.1006/ bbrc.2002.6519

13. LeGeros RZ. Properties of osteoconductive biomaterials: calcium phosphates. Clin Orthop Relat Res. 2002;(395):81-98.

14. Zhao D, Zhang Y, Wang W, et al. Tantalum rod implantation and vascularized iliac grafting for osteonecrosis of the femoral head. Orthopedics. 2013;36(6):789-795. doi:10.3928/01477447-20130122-53

15. Hernigou P, Flouzat-Lachaniette $\mathrm{CH}$, Delambre J, et al. Osteonecrosis repair with bone marrow cell therapies: state of the clinical art. Bone. 2015;70:102-109.
16. Xie H, Kang YJ. Role of copper in angiogenesis and its medicinal implications. Curr Med Chem. 2009;16(10):1304-1314.

17. Eaton-Evans J. Osteoporosis and the role of diet. Br J Biomed Sci. 1994;51(4):358.

18. Rodriguez JP, Rios S, Gonzalez M. Modulation of the proliferation and differentiation of human mesenchymal stem cells by copper. J Cell Biochem. 2002;85(1):92-100.

19. Li H, Yan Y, Wei J, et al. Bone substitute biomedical material of multi-(amino acid) copolymer: in vitro degradation and biocompatibility. Journal of materials science. Mater med. 2011;22(11):2555-2563.

20. Wu C, Zhou Y, Xu M, et al. Copper-containing mesoporous bioactive glass scaffolds with multifunctional properties of angiogenesis capacity, osteostimulation and antibacterial activity. Biomaterials. 2013;34 (2):422-433.

21. Li H, Gong M, Yang A, Ma J, Li X, Yan Y. Degradable biocomposite of nano calcium-deficient hydroxyapatite-multi(amino acid) copolymer. Int J Nanomedicine. 2012;7:1287-1295.

22. Xu HH, Simon CG Jr. Self-hardening calcium phosphate cement-mesh composite: reinforcement, macropores, and cell response. J Biomed Mater Res A. 2004;69(2):267-278.

23. Guo H, Su J, Wei J, Kong H, Liu C. Biocompatibility and osteogenicity of degradable Ca-deficient hydroxyapatite scaffolds from calcium phosphate cement for bone tissue engineering. Acta Biomater. 2009;5(1):268-278.

24. Fuchs S, Jiang X, Gotman I, et al. Influence of polymer content in Ca-deficient hydroxyapatite-polycaprolactone nanocomposites on the formation of microvessel-like structures. Acta Biomater. 2010;6 (8):3169-3177

25. Bianco A, Federico ED, Moscatelli I, et al. Electrospun poly( $\varepsilon$ caprolactone)/Ca-deficient hydroxyapatite nanohybrids: microstructure, mechanical properties and cell response by murine embryonic stem cells. Mater Sci Eng C. 2009;29(6):2063-2071.

26. Li H, Yang L, Dong X, Gu Y, Lv G, Yan Y. Composite scaffolds of nano calcium deficient hydroxyapatite/multi-(amino acid) copolymer for bone tissue regeneration. Journal of materials science. Mater med. 2014;25(5):1257-1265.

27. Tan G, Kang PD, Pei FX. Glucocorticoids affect the metabolism of bone marrow stromal cells and lead to osteonecrosis of the femoral head: a review. Chin Med J. 2012;125(1):134-139.

28. Kim BS, Mooney DJ. Development of biocompatible synthetic extracellular matrices for tissue engineering. Trends Biotechnol. 1998;16 (5):224-230

29. Khan Y, Yaszemski MJ, Mikos AG, Laurencin CT. Tissue engineering of bone: material and matrix considerations. J Bone Joint Surg Am. 2008;90 Suppl 1:36-42.

30. McBane JE, Sharifpoor S, Cai K, Labow RS, Santerre JP. Biodegradation and in vivo biocompatibility of a degradable, polar/ hydrophobic/ionic polyurethane for tissue engineering applications. Biomaterials. 2011;32(26):6034-6044.

31. Ferrara N, Gerber HP, LeCouter J. The biology of VEGF and its receptors. Nat Med. 2003;9(6):669-676.

32. Ueda J, Takai M, Shimazu Y, Ozawa T. Reactive oxygen species generated from the reaction of copper(II) complexes with biological reductants cause DNA strand scission. Arch Biochem Biophys. 1998;357(2):231-239.

33. Burghardt I, Luthen F, Prinz C, et al. A dual function of copper in designing regenerative implants. Biomaterials. 2015;44:36-44.

34. Bejarano J, Caviedes P, Palza H. Sol-gel synthesis and in vitro bioactivity of copper and zinc-doped silicate bioactive glasses and glass-ceramics. Biomed Mater. 2015;10(2):025001.

35. Hu GF. Copper stimulates proliferation of human endothelial cells under culture. J Cell Biochem. 1998;69(3):326-335.

36. Dulgar-Tulloch AJ, Bizios R, Siegel RW. Human mesenchymal stem cell adhesion and proliferation in response to ceramic chemistry and nanoscale topography. J Biomed Mater Res A. 2009;90 (2):586-594. 
37. Valko M, Leibfritz D, Moncol J, Cronin MTD, Mazur M, Telser J. Free radicals and antioxidants in normal physiological functions and human disease. Int J Biochem Cell Biol. 2007;39:44-84.

38. Ewald A, Käppel C, Vorndran E, Moseke C, Gelinsky M, Gbureck U. The effect of $\mathrm{Cu}$ (II)-loaded brushite scaffolds on growth and activity of osteoblastic cells. J Biomed Mater Res A. 2012;100:2392-2400.

39. Lao L, Wang Y, Zhu Y, Zhang Y, Poly GC. lactide-co-glycolide)/hydroxyapatite nanofibrous scaffolds fabricated by electrospinning for bone tissue engineering. J Mater Sci Mater Med. 2011;22(8):1873-1884.

40. Gérard C, Bordeleau LJ, Barralet J, Doillon CJ. The stimulation of angiogenesis and collagen deposition by copper. Biomaterials. 2010;31:824-831.

41. D'Mello S, Elangovan S, Hong L, Ross RD, Sumner DR, Salem AK. Incorporation of copper into chitosan scaffolds promotes bone regeneration in rat calvarial defects. J Biomed Mater Res B Appl Biomater. 2015;103:1044-1049.
42. Liu Y, Berendsen AD, Jia S, et al. Intracellular VEGF regulates the balance between osteoblast and adipocyte differentiation. $J$ Clin Invest. 2012;122(9):3101-3113.

43. Li XD, Chen J, Ruan CC, Zhu DL, Gao PJ. Vascular endothelial growth factor-induced osteopontin expression mediates vascular inflammation and neointima formation via Flt-1 in adventitial fibroblasts. Arterioscler Thromb Vasc Biol. 2012;32(9):2250.

44. Solheim E, Pinholt EM, Talsnes O, Larsen TB, Kirkeby OJ. The relationship between revascularisation and osteogenesis in fresh or demineralised bone grafts. European surgical research. Europaische chirurgische Forschung. Recherches chirurgicales europeennes. 2001;33(1):42-46.

\section{Publish your work in this journal}

The International Journal of Nanomedicine is an international, peerreviewed journal focusing on the application of nanotechnology in diagnostics, therapeutics, and drug delivery systems throughout the biomedical field. This journal is indexed on PubMed Central,

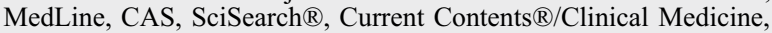

Journal Citation Reports/Science Edition, EMBase, Scopus and the Elsevier Bibliographic databases. The manuscript management system is completely online and includes a very quick and fair peer-review system, which is all easy to use. Visit http://www.dovepress.com/ testimonials.php to read real quotes from published authors. 